\title{
Perda de Amônia por Volatilização em Pastagem de Capim-Tanzânia Adubada com Uréia no Verão 1
}

\author{
Geraldo Bueno Martha Júnior ${ }^{2}$, Moacyr Corsi ${ }^{3}$, Paulo Cesar Ocheuze Trivelin ${ }^{4}$, Lourival Vilela², \\ Taís Leite Ferreira Pinto ${ }^{5}$, Gleuber Mariano Teixeira ${ }^{6}$, Ciro Staino Manzoni ${ }^{6}$, Luis Gustavo Barioni ${ }^{2}$
}

RESUMO - Parte do nitrogênio $(\mathrm{N})$ do fertilizante aplicado à pastagem pode ser perdida do sistema e, em pastagens tropicais, a volatilização de amônia $\left(\mathrm{NH}_{3}\right)$ é uma das principais vias de perda. Objetivou-se, com o presente estudo, estimar a perda de $\mathrm{N}-\mathrm{NH}_{3}$ por volatilização em pastagem de Panicum maximum cv. Tanzânia adubada com uréia durante o verão. Adotou-se um delineamento inteiramente casualizado, com medidas repetidas no tempo e três repetições. Nas parcelas, encontravam-se as doses de N-uréia (40, 80 e 120 kg/ha de N-uréia) e, nas subparcelas, o período depois da adubação nitrogenada (1, 5 e 9 dias). A interação entre o nível de adubação e o período depois da aplicação de uréia foi significativa para as variáveis volatilização acumulada de $\mathrm{N}_{-} \mathrm{NH}_{3}$ e taxa diária de volatilização de $\mathrm{N}-\mathrm{NH}_{3}$. A combinação de elevada umidade do solo, ausência de chuvas durante o primeiro dia depois da adubação e alta temperatura elevada determinaram elevadas perdas de amônia por volatilização. A perda acumulada de $\mathrm{N}-\mathrm{NH}_{3}$ no período representou $48 \%$, 41\% e 42\% do N aplicado nas adubações com 40, 80 e 120 kg/ha de N-uréia, respectivamente. A volatilização acumulada de N-NH 3 (kg/ha) aumentou, enquanto a taxa diária de volatilização de $\mathrm{N}-\mathrm{NH}_{3}$ diminuiu com o aumento do tempo depois da adubação.

Palavras-chave: fertilizante nitrogenado, Panicum maximum, pastagem

\section{Ammonia Volatilization Loss in Tanzaniagrass Pasture Fertilized with Urea in the Summer}

\begin{abstract}
Part of the fertilizer nitrogen (N) applied to pasture may be lost from the system and, in tropical pastures, the volatilization of ammonia $\left(\mathrm{NH}_{3}\right)$ is one of the major pathways of loss. The present study aimed to estimate the $\mathrm{NH}_{3}-\mathrm{N}_{\text {volatilization }}$ loss in Panicum maximum cv. Tanzania pasture fertilized with urea during the summer. A completely randomized design, following a repeated measure arrangement, with three replicates was used. The plots were represented by urea levels (40, 80 and $120 \mathrm{~kg} / \mathrm{ha}$ urea$\mathrm{N}$ ) and the subplots by the time after fertilization (1, 5 and 9 days). The interaction between level of fertilization and time after urea application was significant for accumulated $\mathrm{NH}_{3}-\mathrm{N}$ volatilization loss and daily $\mathrm{NH}_{3}-\mathrm{N}$ volatilization loss rate. The combination of high soil water content, lack of rainfall in the day following fertilization and high temperature determined high ammonia volatilization losses. The accumulated $\mathrm{NH}_{3}-\mathrm{N}$ loss in the period represented $48 \%, 41 \%$ and $42 \%$ of the applied $\mathrm{N}$ in 40, 80 and $120 \mathrm{~kg} / \mathrm{ha}$ urea-N fertilizations, respectively. The accumulated $\mathrm{NH}_{3}-\mathrm{N}$ loss (kg/ha) increased, while the daily $\mathrm{NH}_{3}-\mathrm{N}$ volatilization loss rate decreased with the increase in time after fertilization.
\end{abstract}

Key Words: nitrogenous fertilizer, Panicum maximum, pasture

\section{Introdução}

Parte do nitrogênio (N) do fertilizante aplicado à pastagem é freqüentemente perdida do sistema, o que reduz a eficiência de uso do $\mathrm{N}$ aplicado e, potencialmente, diminui a lucratividade dos empreendimentos de pecuária baseados na exploração de pastagens adubadas com fertilizantes nitrogenados. Em pasta- gens tropicais, a volatilização de amônia $\left(\mathrm{NH}_{3}\right)$ é uma das principais vias de perda, principalmente quando a uréia é aplicada a lanço e em cobertura no final do período das chuvas (Martha Jr., 1999; Primavesi et al., 2001). Embora a incorporação de uréia ao solo a 4 a $5 \mathrm{~cm}$ de profundidade seja efetiva na redução das perdas de $\mathrm{N}-\mathrm{NH}_{3}$ por volatilização (Ernst \& Massey, 1960; Hargrove, 1988), essa prática não é recomen-

\footnotetext{
1 Parte da tese de Doutorado apresentada pelo primeiro autor à Universidade de São Paulo, Escola Superior de Agricultura "Luiz de Queiroz" (USP/ESALQ). Pesquisa financiada pela Fundação de Amparo à Pesquisa do Estado de São Paulo (FAPESP).

2 Pesquisador-Embrapa Cerrados, BR 020, km 18, Caixa Postal 08223, CEP: 73301-970, Planaltina-DF. E.mail: gbmartha@cpac.embrapa.br; Ivilela@cpac.embrapa.br;barioni@cpac.embrapa.br

3 Professor Titular - Departamento de Zootecnia, USP/ESALQ, Caixa Postal 09, CEP: 13418-900,Piracicaba-SP.E.mail: moa@esalq.usp.br

4 Professor Associado - Laboratório de Isótopos Estáveis, USP, Centro de Energia Nuclear na Agricultura (USP/CENA), Caixa Postal, 96, CEP: 13400-970, Piracicaba-SP. Bolsista do CNPq. E.mail: pcotrive@cena.usp.br

5 Graduando em Engenharia Agronômica - USP/ESALQ.

6 Mestrando - Laboratório de Isótopos Estáveis, USP/CENA. Bolsista Fapesp.
} 
dada para pastagens cespitosas, porque prejudica o sistema radicular da planta forrageira, diminuindo o vigor de rebrota subseqüente da pastagem (Corsi \& Nussio, 1993; Corsi et al., 2001).

Entretanto, no Brasil, os fertilizantes nitrogenados são normalmente aplicados em cobertura, sem incorporação do fertilizante no solo. Desse modo, é necessário desenvolver alternativas para reduzir as perdas e maximizar o uso do $\mathrm{N}$-fertilizante nessas condições. Contudo, avanços expressivos para o entendimento do ciclo do $\mathrm{N}$ e para o desenvolvimento de protocolos práticos de manejo desse nutriente só serão observados quando estimativas confiáveis da perda do $\mathrm{N}$ aplicado forem conhecidas. Intrínseca à essa argumentação está a necessidade dessas estimativas serem realizadas em campo, uma vez que os resultados gerados em laboratório ou em casa-de-vegetação, ainda que úteis para o entendimento de alguns processos, são de aplicabilidade limitada e contestável para plantas crescendo no campo. Ressalta-se, ainda, o limitado número de estudos realizados no país com esse propósito (Martha Jr., 1999; Primavesi et al., 2001) e a inexistência de trabalhos com Panicum maximum cv. Tanzânia, forrageira amplamente utilizada em sistemas intensivos de produção de bovinos em pastagem no país.

O presente estudo foi conduzido com o objetivo de estimar as perdas de $\mathrm{N}-\mathrm{NH}_{3}$ por volatilização em pastagem de capim-Tanzânia adubada com uréia durante um ciclo de pastejo de verão.

\section{Material e Métodos}

O experimento foi realizado em pastagem irrigada de Panicum maximum cv. Tanzânia, estabelecida em área experimental da Escola Superior de Agricultura "Luiz deQueiroz", Universidade de São Paulo, PiracicabaSP (altitude 580 m; 22o41'30" S; 47o38'00" W), durante um ciclo de pastejo de verão.

O padrão e a extensão de volatilização de $\mathrm{N}-\mathrm{NH}_{3}$, em razão de diferentes doses de adubação e de períodos depois da aplicação de uréia, foram avaliados na área não vegetada de parcelas (1 m x $1 \mathrm{~m}$ ), distribuídas aleatoriamente em um piquete de $1.333 \mathrm{~m}^{2}$. A área não vegetada, que representou 70\% da superfície da pastagem, correspondeu à superfície do solo não ocupada pela área basal das touceiras. No início das avaliações, no dia seguinte à retirada dos animais dos piquetes, a massa de forragem residual foi de, aproximadamente, $3.500 \mathrm{~kg} / \mathrm{ha}$ de massa seca verde e a altura desse resíduo pós-pastejo foi de cerca de $40 \mathrm{~cm}$. A massa seca de material morto presente na área não vegetada ("litter") foi de, aproximadamente, $1.500 \mathrm{~kg} / \mathrm{ha}$.

O delineamento foi o inteiramente casualizado, com medidas repetidas no tempo e três repetições. Nas parcelas, encontravam-se as doses de N-uréia (40, 80 e 120 kg/ha de $\mathrm{N}$-uréia) e, nas subparcelas, o período depois da adubação nitrogenada (1, 5 e 9 dias). O tratamento controle ( $0 \mathrm{~kg} / \mathrm{ha}$ de $\mathrm{N})$ foi considerado como branco (i.e., as perdas de $\mathrm{N}-\mathrm{NH}_{3}$ que ocorrem no sistema sem a influência do fertilizante nitrogenado) e usado para corrigir as perdas de $\mathrm{N}-\mathrm{NH}_{3}$ nas adubações com 40, 80 e $120 \mathrm{~kg} /$ ha de N. Detalhes adicionais do protocolo experimental foram apresentados por Lara Cabezas \& Trivelin (1990) e Lara Cabezas et al. (1999).

Algumas características climáticas registradas no período correspondente ao experimento de volatilização de $\mathrm{N}-\mathrm{NH}_{3}$ (10/01 a 19/01) são apresentadas na Tabela 1.

Durante o experimento, a umidade do solo na camada de 0 a $20 \mathrm{~cm}$ de profundidade representou 90 a $105 \%$ da capacidade de campo, equivalente a -10 kPa. Por ocasião da instalação dos tratamentos (adubação nitrogenada; 10/01), verificou-se que, na superfície, o solo mostrava-se encharcado (presença de poças d'água). Detalhes adicionais da área experimental foram apresentados por Martha Jr. (2003).

O solo da área experimental era um Podzólico Vermelho-Escuro (Argissolo vermelho) de textura argilosa, cujas principais características químicas podem ser descritas como: matéria orgânica - 25 g/kg; $\mathrm{pH}$ (CaCl2) - 5,1; P (resina) - 19,1 mg/dm³ K 4,2 mmolc/dm 3 ; Ca - $41 \mathrm{mmolc} / \mathrm{dm} 3 ; \mathrm{Mg}$ $21 \mathrm{mmolc} / \mathrm{dm}^{3} ; \mathrm{H}+\mathrm{Al}-35 \mathrm{mmolc} / \mathrm{dm}^{3}$. A correção e a adubação do solo foram previamente feitas para se atingir 70\% de saturação por bases, $20 \mathrm{mg} / \mathrm{dm}^{3}$ de P no solo e proporção de K no solo de 3 a 5\% da CTC, conforme sugerido por Corsi \& Nussio (1993). Adicionalmente ao $\mathrm{N}$, cada parcela foi adubada com $10 \mathrm{~kg} / \mathrm{ha}$ de enxofre na forma de sulfato de sódio.

Uma solução de uréia (500 mL da solução contendo o fertilizante seguida por mais $500 \mathrm{~mL}$ de água), de acordo com os tratamentos, foi aplicada às parcelas, com pulverizador comum de líquidos, no início da manhã do dia seguinte à saída dos animais do piquete (10/01). A eficiência de adubações nitrogenadas nas formas líquida e sólida tem sido equiparável. Watson et al. (1992) observaram que a aplicação superficial

R. Bras. Zootec., v.33, n.6, p.2240-2247, 2004 (Supl. 3) 
Tabela 1 - Condições climáticas durante o período experimental Table 1 - Climatic conditions during the experimental period

\begin{tabular}{|c|c|c|c|c|c|c|}
\hline \multirow[t]{2}{*}{$\begin{array}{l}\text { Dia } \\
\text { Day }\end{array}$} & \multirow{2}{*}{$\begin{array}{l}\text { Precipitação } \\
\text { Rainfall } \\
\text { (mm) }\end{array}$} & \multirow{2}{*}{$\begin{array}{l}\text { Radiação } \\
\text { Radiation } \\
\left(\mathrm{cal} / \mathrm{cm}^{2}\right)\end{array}$} & \multirow{2}{*}{$\begin{array}{l}\text { Umidade relativa } \\
\text { Air humidity } \\
\text { (\%) }\end{array}$} & \multirow{2}{*}{$\begin{array}{l}\text { Evaporação } \\
\text { Evaporation } \\
(\mathrm{mm})\end{array}$} & \multicolumn{2}{|c|}{$\begin{array}{l}\text { Temperatura }\left({ }^{\circ} \mathrm{C}\right) \\
\text { Temperature }\left({ }^{\circ} \mathrm{C}\right)\end{array}$} \\
\hline & & & & & $\begin{array}{l}\text { Mínima } \\
\text { Minimum }\end{array}$ & $\begin{array}{c}\text { Máxima } \\
\text { Maximum }\end{array}$ \\
\hline 06/01 & 18,3 & 547 & 88 & 6,2 & 19,7 & 31,8 \\
\hline 07/01 & 3,9 & 222 & 100 & 1,0 & 20,6 & 26,0 \\
\hline 08/01 & 44,0 & 369 & 96 & 6,2 & 20,3 & 31,0 \\
\hline 09/01 & 8,5 & 248 & 98 & 5,7 & 18,5 & 28,8 \\
\hline $10 / 01^{1}$ & 0,0 & 359 & 88 & 4,2 & 18,4 & 29,0 \\
\hline $11 / 01^{2}$ & 0,0 & 227 & 92 & 5,5 & 19,7 & 25,7 \\
\hline 12/01 & 33,2 & 302 & 96 & 5,7 & 19,2 & 27,7 \\
\hline $13 / 01$ & 28,1 & 183 & 100 & 5,3 & 19,0 & 25,1 \\
\hline $14 / 01$ & 6,4 & 306 & 98 & 4,0 & 20,7 & 28,2 \\
\hline $15 / 01^{2}$ & 2,4 & 356 & 97 & 1,3 & 20,2 & 27,4 \\
\hline 16/01 & 0,0 & 326 & 87 & 5,0 & 19,0 & 24,5 \\
\hline $17 / 01$ & 0,0 & 591 & 80 & 8,0 & 13,8 & 28,0 \\
\hline 18/01 & 0,0 & 477 & 82 & 2,3 & 16,6 & 26,9 \\
\hline 19/012 & 2,7 & 364 & 92 & 5,1 & 16,7 & 25,3 \\
\hline
\end{tabular}

${ }^{1}$ Aplicação do fertilizante nitrogenado (Application of fertilizer $N$ ).

2 Determinação da volatilização de $\mathrm{N}-\mathrm{NH}_{3}$ (Determination of $\mathrm{NH}_{3}-\mathrm{N}$ volatilization).

de uréia em pastagem de Lolium perenne, na forma líquida, não resultou em menores perdas de amônia por volatilização, em comparação com a uréia aplicada em forma granulada. De maneira semelhante, Volk(1959) observou que as perdas de N-uréia aplicada superficialmente em pastagem de Cynodon dactylon, na forma de solução, foi similar às perdas da uréia aplicada na forma de grânulo.

As medidas de volatilização de $\mathrm{N}-\mathrm{NH}_{3}$ foram realizadas por meio de coletores semi-aberto estáticos (Lara Cabezas et al., 1999), que foram locados na área não vegetada da parcela, logo depois da aplicação dos tratamentos. Os coletores de $\mathrm{N}-\mathrm{NH}_{3}$ utilizados nesse experimento foram descritos detalhadamente por Lara Cabezas \& Trivelin (1990).

Resumidamente, os coletores consistiram-se de uma estrutura tubular de PVC transparente flexível (0,35 m de altura x $0,144 \mathrm{~m}$ de diâmetro interno $\mathrm{x} 1 \mathrm{~mm}$ de espessura), montada sobre suportes de PVC aleatoriamente colocados na área não vegetada da parcela (dois coletores por parcela) e enterrados no solo a profundidade de 3 a $5 \mathrm{~cm}$. Na união do suporte com o coletor, utilizou-se massa para calafetar, com o objetivo de vedar as superfícies do suporte e do coletor, a fim de evitar que o $\mathrm{N}-\mathrm{NH}_{3}$ que volatilizava do solo fosse perdido para fora do coletor. Na extremidade oposta ao solo, colocou-se um chapéu de PVC transparente, para evitar a incidência de chuvas no interior do coletor.

\footnotetext{
R. Bras. Zootec., v.33, n.6, p.2240-2247, 2004 (Supl. 3)
}

Cada coletor apresentava suportes no seu interior para sustentar duas espumas (densidade $0,02 \mathrm{~g} / \mathrm{cm}^{3}$ ), que antes de serem instaladas nos coletores foram embebidas com $35 \mathrm{~mL}$ de solução de ácido sulfúrico $0,5 \mathrm{~N}$ e glicerina $(3 \% \mathrm{v} / \mathrm{v})$ com o objetivo de absorver o $\mathrm{N}-\mathrm{NH}_{3}$. A espuma superior, posicionada a $31 \mathrm{~cm}$ do solo, permite a coleta da $\mathrm{N}-\mathrm{NH}_{3}$ da atmosfera, evitando que a espuma inferior (15,5 cm do solo), que capta o $\mathrm{N}-\mathrm{NH}_{3}$ volatilizando da superfície do solo, seja contaminada (Lara Cabezas \& Trivelin, 1990). Em cada momento de amostragem, novas espumas embebidas em ácido sulfúrico, conforme procedimento indicado acima, foram repostas.

Inicialmente, foram planejadas cinco medidas de volatilização de $\mathrm{N}-\mathrm{NH}_{3}$ (1, 4, 7, 11 e 15 dias depois da adubação), porém, em razão das fortes chuvas que ocorreram nos dias subseqüentes à adubação (Tabela 1), o protocolo de amostragem foi alterado para os dias 1 (11/jan), 5 (15/jan) e 9 (19/jan) depois da adubação, uma vez que chuvas superiores a 10 a 20 mm reduzem, substancialmente, o processo de volatilização de $\mathrm{N}-\mathrm{NH}_{3}$ (Black et al., 1987). Após o segundo período de avaliação, no quinto dia depois da aplicação do fertilizante nitrogenado, repôs-se água dentro dos coletores de $\mathrm{N}^{-\mathrm{NH}_{3}}$, em quantidades equivalentes às chuvas registradas no período (cerca de $70 \mathrm{~mm}$; Tabela 1 ), no intuito de evitar erros decorrentes de diferenças na umidade do solo dentro e fora dos coletores, conforme proposto por Lara Cabezas et al. (1999). 
Em cada período de coleta, as espumas inferiores, que capturaram o $\mathrm{N}-\mathrm{NH}_{3}$ volatilizado do solo, foram acondicionadas em sacos plásticos devidamente identificados, que foram vedados e armazenados sob refrigeração até o momento da análise. No laboratório, as espumas foram retiradas, individualmente, do refrigerador para extração forçada de $\mathrm{N}-\mathrm{NH}_{3}$. Cada espuma foi colocada sobre um papel-filtro posicionado sobre um funil de porcelana e, com o auxílio de uma bomba de vácuo, lavou-se a espuma, com aproximadamente, $400 \mathrm{~mL}$ de água desionizada. Durante o processo de extração, os materiais que entraram em contato com a espuma também foram lavados com água desionizada para evitar possíveis perdas do $\mathrm{N}-\mathrm{NH}_{3}$ coletado no campo. Além disso, todo o processo foi feito com o auxílio de uma pinça, no sentido de evitar a contaminação do material a ser analisado. Entre a extração de $\mathrm{N}-\mathrm{NH}_{3}$ de duas espumas sucessivas, todo o material foi lavado, primeiramente com água de torneira e, subseqüentemente, com água desionizada.

A solução extraída de cada espuma (cerca de 450 a $500 \mathrm{~mL}$ ) foi acidificada com $1 \mathrm{~mL}$ de ácido sulfúrico $1 \mathrm{~N}$ colocada em um becker para concentrar em estufa a $60^{\circ} \mathrm{C}$. Depois de dois dias na estufa, as amostras estavam com volume de cerca de 50 a $70 \mathrm{~mL}$ e, então, foram transferidas para um balão volumétrico de $200 \mathrm{~mL}$, para determinação de $\mathrm{N}_{-} \mathrm{NH}_{3}$. Durante o processo de transferência da solução contendo $\mathrm{N}-\mathrm{NH}_{3}$, do becker para o balão volumétrico, todos os materiais que entraram em contato com a solução com água desionizada foram lavados. A determinação de $\mathrm{N}-\mathrm{NH}_{3}$ foi feita por destilação e titulação, sendo que a solução destilada foi recebida em ácido bórico 2\% e titulada com ácido sulfúrico 0,1 N.

Como os coletores estavam posicionados na área da pastagem não ocupada pelas plantas, os resultados foram expressos com base na área não vegetada da pastagem (i.e. $70 \%$ da superfície do pasto), em que a adubação nitrogenada eqüivaleu a 28, 56 e 84 kg/ha de $\mathrm{N}$ para os tratamentos adubados com 40, 80 e $120 \mathrm{~kg} / \mathrm{ha}$ de $\mathrm{N}$, respectivamente. A perda acumulada de amônia por volatilização (kg/ha de área não vegetada de N$\mathrm{NH}_{3}$ ) foi calculada a partir de medidas tomadas nos dias 1, 1+5 e 1+5+9. A taxa de perda diária de amônia por volatilização (kg/ha de área não vegetada/dia de $\mathrm{N}-\mathrm{NH}_{3}$ ) foi calculada para todos os períodos (i.e., do dia da adubação ao dia 1, do 1 ao dia 5 e do 5 ao 9).

Uma das principais críticas a coletores fechados e semi-abertos de $\mathrm{N}-\mathrm{NH}_{3}$ refere-se à geração de condições artificiais no interior do coletor, o que prejudica os fluxos de $\mathrm{N}-\mathrm{NH}_{3}$ da superfície do solo para a atmosfera (Sharpe \& Harper, 1995), podendo ocorrer, inclusive, a reabsorção de $\mathrm{N}-\mathrm{NH}_{3}$ pelo solo. $\mathrm{Na}$ ausência de correção dos valores determinados de $\mathrm{N}-\mathrm{NH}_{3}$, os estudos com base no uso desses aparelhos não possibilitam quantificar as perdas de $\mathrm{N}-\mathrm{NH}_{3}$ que efetivamente ocorrem no campo. Nesse sentido, as equações de calibração apresentadas por Lara Cabezas et al. (1999), para expressar a volatilização de $\mathrm{N}-\mathrm{NH}_{3}$ em áreas não vegetadas, sem a influência dos coletores (i.e. as perdas reais de $\mathrm{N}$ $\mathrm{NH}_{3}$ sem a interferência do coletor), foram utilizadas.

Os dados foram testados quanto à normalidade dos erros e homogeneidade de variâncias e as análises estatísticas foram realizados utilizando-se os recursos do pacote estatístico SAS (SAS, 1989). As discussões apresentadas a seguir foram feitas com base na derivada primeira das equações apresentadas nas figuras.

\section{Resultados e Discussão}

A interação entre a dose de N-uréia e o período depois da aplicação do adubo foi significativa para as variáveis volatilização acumulada de $\mathrm{N}-\mathrm{NH}_{3}$ $(\mathrm{P}<0,0025)$ e taxa diária de volatilização de $\mathrm{N}-\mathrm{NH}_{3}$ $(\mathrm{P}<0,0001)$. A volatilização acumulada aumentou com o período depois da adubação, apesar de as taxas de perda de amônia terem sido decrescentes ao longo do período estudado. Constatou-se maiores valores de volatilização acumulada (kg/ha) nas doses mais elevadas de N-uréia (Figura 1).

Pelos modelos matemáticos apresentados na Figura 1, observa-se que não haveria acúmulo adicional na quantidade de $\mathrm{N}-\mathrm{NH}_{3}$ volatilizada depois de 14, 23 e 35 dias da adubação nos tratamentos fertilizados com 40, 80 e $120 \mathrm{~kg} / \mathrm{ha}$ de $\mathrm{N}$-uréia, respectivamente. Considerando a quantidade de $\mathrm{N}$-uréia aplicada na área não vegetada da pastagem, de 28, 56 e 84 kg/ha, calcula-se que a perda acumulada de $\mathrm{N}-\mathrm{NH}_{3}$, no período, eqüivaleu a $48 \%, 41 \%$ e $42 \%$ do $\mathrm{N}$ aplicado, respectivamente.

A ausência de efeito da dose de $\mathrm{N}$-uréia $(\mathrm{P}>0,05)$ sobre a perda de $\mathrm{N}-\mathrm{NH}_{3}$, expressa como porcentagem do $\mathrm{N}$ aplicado, encontra suporte nas considerações de Hargrove (1988) de que, uma vez que a volatilização de $\mathrm{N}-\mathrm{NH}_{3}$ pode ser linear ou exponencial (como observado no padrão de resposta da Figura 1), as perdas relativas (porcentagem do $\mathrm{N}$ aplicado) podem diminuir, permanecerem constantes ou aumentarem com níveis crescentes de aplicação do fertilizante nitrogenado.

R. Bras. Zootec., v.33, n.6, p.2240-2247, 2004 (Supl. 3) 
Observa-se, ainda, que a perda de $\mathrm{N}-\mathrm{NH}_{3}$ medida no dia seguinte à adubação foi a principal responsável pela volatilização acumulada de $\mathrm{N}^{-\mathrm{NH}_{3}}$ no período, uma vez que, nas avaliações efetuadas nos dias 5 e 9, não foram constatadas diferenças na taxa diária de volatilização nas adubações com 40, 80 e 120 kg/ha de N-uréia (Figura 2).

As taxas diárias de volatilização de $\mathrm{N}-\mathrm{NH}_{3}$, para uma dada dose do fertilizante, diminuíram $(\mathrm{P}<0,05)$ de maneira exponencial nos tempos de avaliação. Tomando como referencial a medida de volatilização realizada no dia 1 , calcula-se, pelas equações apresentadas na Figura 3, que, no período (do dia 1 ao dia 9), a redução na taxa de volatilização diária de amônia foi de 6, 8 e 10 vezes nas adubações com 40, 80 e 120 kg/ha de N-uréia, respectivamente. Esse comportamento é coerente com o padrão de volatilização acumulada de $\mathrm{N}-\mathrm{NH}_{3}$ apresentado na Figura 1.

Os resultados referentes à volatilização acumulada de $\mathrm{N}-\mathrm{NH}_{3}$ e às taxas diárias de volatilização podem ser explicados pela ação conjunta de fatores de solo e de clima que proporcionaram elevada concen-

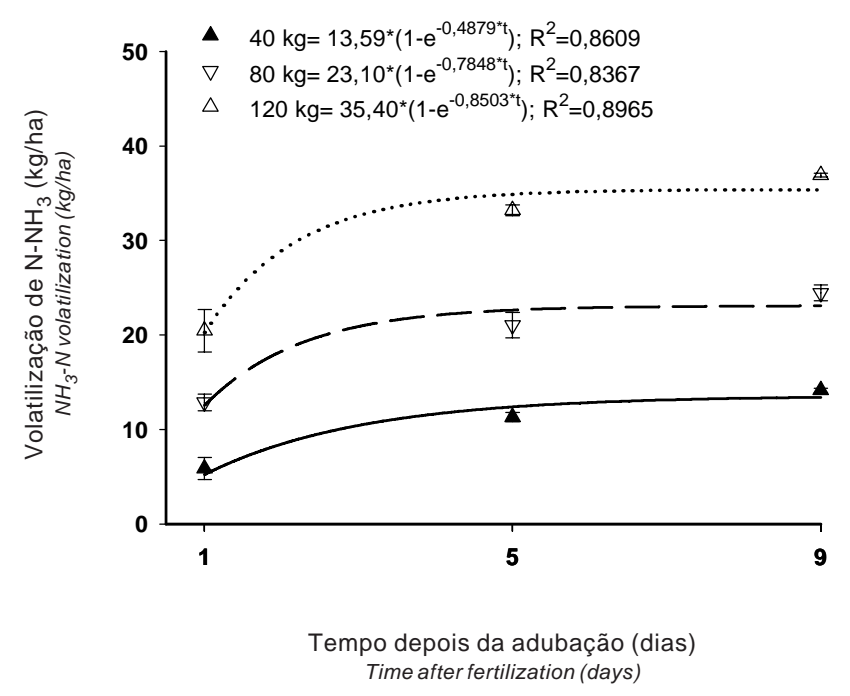

Figura 1 - Perda acumulada de $\mathrm{N}-\mathrm{NH}_{3}$ (kg/ha) em pastagem de capim-Tanzânia adubada com 40, 80 e 120 kg/ha de N-uréia. Nas equações, "t" representa o tempo (dias) depois da aplicação de uréia.

Figure 1 - Acummulated $\mathrm{NH}_{3}-\mathrm{N}$ loss $(\mathrm{kg} / \mathrm{ha}$ ) in Tanzaniagrass pasture fertilized with 40,80 and $120 \mathrm{~kg} \mathrm{~N}$-urea/ha. In the equations, " $t$ " represents the time after urea application.

R. Bras. Zootec., v.33, n.6, p.2240-2247, 2004 (Supl. 3)

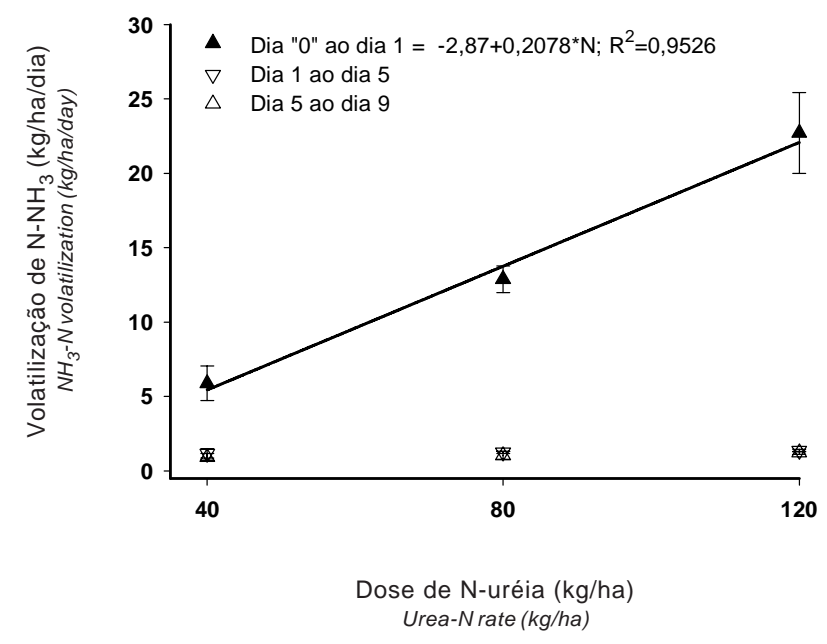

Figura 2 - Taxa diária de volatilização de $\mathrm{N}-\mathrm{NH}_{3}$ (kg/ha/dia) em pastagem de capim-Tanzânia adubada com 40, 80 e 120 kg/ha de N-uréia. Na equação, "N" representa a dose de $\mathrm{N}$-uréia.

Figure 2 - Daily $\mathrm{NH}_{3}-\mathrm{N}$ volatilization rate $(\mathrm{kg} / \mathrm{ha} /$ day) in Tanzaniagrass pasture fertilized with 40,80 and $120 \mathrm{~kg} \mathrm{~N}$-urea/ha. In the equation, "N" represents the urea- $N$ rate.

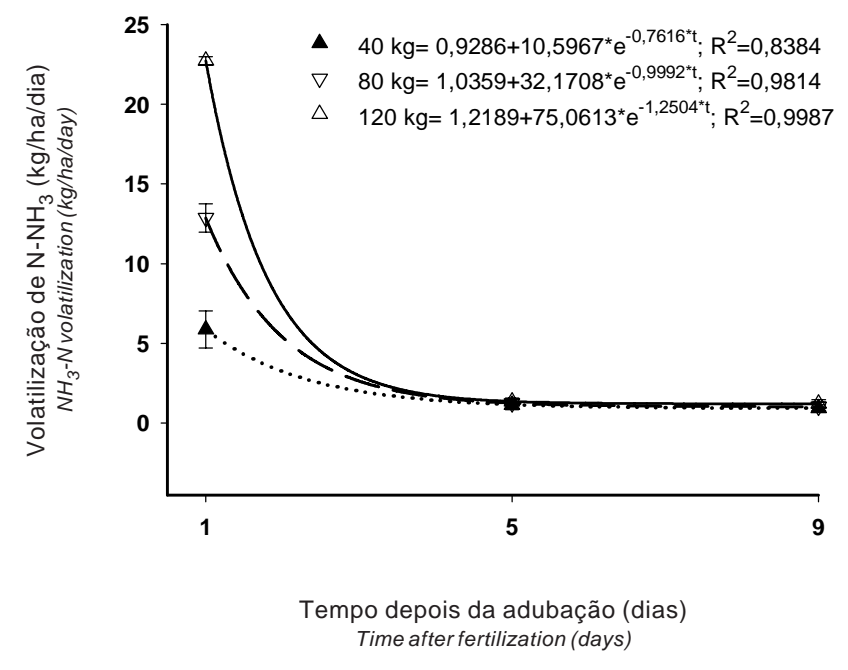

Figura 3 - Perda diária de $\mathrm{N}-\mathrm{NH}_{3}$ (kg/ha/dia) em pastagem de capim-Tanzânia adubada com 40, 80 e 120 kg/ha de N-uréia. Nas equações, "t" representa o tempo (dias) depois da aplicação de uréia.

Figure 3 - Daily $\mathrm{NH}_{3}-\mathrm{N}$ loss ( $\mathrm{kg} / \mathrm{ha} /$ day) in Tanzaniagrass pasture fertilized with 40, 80 and $120 \mathrm{~kg} \mathrm{~N}$-urea/ha. In the equations, " $t$ " represents the time after urea application. 
tração de $\mathrm{N}-\mathrm{NH}_{3}$ próxima à superfície do solo e alta taxa de perda de água do solo e, dessa maneira, determinaram um elevado potencial de perda de $\mathrm{N}-\mathrm{NH}_{3}$ para fora do sistema solo-planta.

Pode-se citar, como fatores de solo, o elevado potencial de hidrólise da uréia em solos vegetados por pastagens, a elevação do pH no local de hidrólise da uréia e os elevados níveis de conteúdo de água no solo (Ernst \& Massey, 1960; Black et al., 1985; Hargrove, 1988). Como fatores de clima, destacam-se a elevada temperatura e a falta de chuva no dia subseqüente à aplicação do fertilizante (Black et al., 1987; Bouwmeester et al., 1985; Hargrove, 1988).

A expressiva redução na taxa diária de volatilização nos primeiros dias depois da adubação pode indicar que a amônia moveu-se para camadas mais profundas do solo, onde o processo de volatilização de $\mathrm{N}^{-\mathrm{NH}_{3}}$ é reduzido (Rodrigues \& Kiehl, 1986; 1992; Hargrove, 1988). É interessante notar que a reposição de água dentro dos coletores, no dia 5 depois da adubação (o equivalente a $70 \mathrm{~mm}$ de chuva), não reduziu adicionalmente a taxa de perda diária de $\mathrm{N}_{-} \mathrm{NH}_{3}$ (Figuras 2 e 3) e não elevou, de maneira expressiva, as perdas acumuladas de $\mathrm{N}-\mathrm{NH}_{3}$ (Figura 1).

Entretanto, pode-se argumentar que as chuvas verificadas entre os dias 1 e 5 depois da adubação, em particular nos dias 2 e 3 (Tabela 1 ), indicam que a não reposição de água, nesse período, determinou superestimativa dos valores de volatilização acumulada e de taxa diária de perda de $\mathrm{N}-\mathrm{NH}_{3}$. O fato de as perdas de amônia se concentrarem nos primeiros dias depois da adubação de certa forma dão suporte a essa afirmação. Com efeito, considerando a área não vegetada da pastagem e as equações da Figura 1, calcula-se que as perdas medidas no dia 1 depois da adubação, para as doses de 40, 80 e $120 \mathrm{~kg} / \mathrm{ha}$ de Nuréia, responderam por 39\%, 54\% e 57\% das perdas totais de $\mathrm{N}-\mathrm{NH}_{3}$ determinadas. No dia 3 , as respectivas perdas já contabilizavam 78\%, 91\% e 92\% das perdas totais de $\mathrm{N}-\mathrm{NH}_{3}$.

Ressalta-se que o padrão e a extensão de volatilização de amônia observados netse estudo estão de acordo com outros experimentos realizados com gramíneas tropicais (Martha Jr., 1999; Primavesi et al., 2001), indicando que grandes quantidades do N proveniente da uréia aplicada superficialmente em pastagens podem ser rapidamente perdidas do sistema soloplanta. A extensão e o padrão das perdas de $\mathrm{N}-\mathrm{NH}_{3}$ proveniente da uréia aplicada superficialmente à pastagem sinalizam que, durante o verão (elevadas tem- peraturas) e na ausência de chuvas imediatamente depois da adubação (Tabela 1), as medidas de manejo para controlar as perdas de $\mathrm{N}-\mathrm{NH}_{3}$ só serão efetivas se: 1) praticadas logo depois da aplicação do fertilizante nitrogenado, preferivelmente antes de 1 dia depois da adubação; 2) considerarem a manipulação da uréia (misturas de sais com uréia); ou 3) utilizarem outra fonte de fertilizante nitrogenado que não a uréia.

Embora a incorporação da uréia ao solo reduza sensivelmente as perdas de $\mathrm{N}-\mathrm{NH}_{3}$ (Ernst \& Massey, 1960; Rodigues \& Kiehl, 1986), a restrição quanto à incorporação da uréia em pastagens cespitosas, no sentido de não comprometer a perenidade da pastagem (Corsi \& Nussio, 1993; Corsi et al., 2001), evidencia a necessidade de outras alternativas de manejo para reduzir as perdas de amônia por volatilização e, conseqüentemente, aumentar a eficiência de uso do N-uréia pelo capim-Tanzânia.

Para contornar o problema das perdas de $\mathrm{N}-\mathrm{NH}_{3}$ em pastagens, poder-se-iam utilizar sais amoniacais, menos propensos a perder o $\mathrm{N}$ na forma de $\mathrm{N}-\mathrm{NH}_{3}$, em comparação com a uréia (Martha Jr., 1999; Primavesi et al., 2001). Contudo, como a uréia é o fertilizante nitrogenado mais barato no mercado, cabe ao produtor/técnico decidir se vale a pena pagar mais para minimizar os riscos de perda de amônia por volatilização.

Misturas de sais com uréia também poderiam ser utilizadas para reduzir as perdas de $\mathrm{N}-\mathrm{NH}_{3}$ por volatilização, mas as evidências sobre a efetividade dessa prática, no aumento da eficiência de uso do N da uréia, não são consistentes (Rappaport \& Axley, 1984; Oliveira, 2001; Vitti et al., 2001). Embora a relação $\mathrm{N}: \mathrm{S}$ dos tratamentos (4:1, 8:1 e 12:1 para os tratamentos adubados com 40, 80 e $120 \mathrm{~kg} / \mathrm{ha}$ de $\mathrm{N}$-uréia, respectivamente) tenha variado neste experimento, não foi possível separar o efeito de doses crescentes do fertilizante nitrogenado dos potenciais benefícios da redução das perdas de $\mathrm{N}-\mathrm{NH}_{3}$ advindos da menor relação N:S no fertilizante (Lara Cabezas et al., 1992).

O uso de irrigação logo depois da adubação também é uma prática efetiva na redução das perdas de $\mathrm{N}-\mathrm{NH}_{3}$ do sistema solo-planta (Bouwmeester et al., 1985; Black et al., 1987), mas a aplicação de água de irrigação, geralmente, é feita com base na água disponível no solo e, na maioria das vezes, a decisão do momento de irrigação não considera a aplicação do fertilizante nitrogenado. Embora a irrigação possa

R. Bras. Zootec., v.33, n.6, p.2240-2247, 2004 (Supl. 3) 
ser praticada considerando o manejo do fertilizante nitrogenado em associação à água disponível no solo, a irrigação em solos com níveis de água próximos à capacidade campo pode determinar perdas elevadas de N por desnitrificação (Linn \& Doran, 1984; Granli \& Bockman, 1995). Nessas condições, a irrigação poderia reduzir as perdas de $\mathrm{N}$ por volatilização de amônia, mas, em contrapartida, poderia potencializar as perdas do elemento por desnitrificação e, em especial no caso de solos arenosos e rasos, potencializaria, também, as perdas de $\mathrm{N}$ pela lixiviação de nitrato.

Com relação ao presente experimento, pode-se inferir que, apesar de as perdas de $\mathrm{N}-\mathrm{NH}_{3}$ terem sido substancialmente reduzidas a partir do dia seguinte à adubação (Figura 3), a perda de N por desnitrificação provavelmente manteve-se em patamares altos em razão da manutenção da umidade do solo em níveis elevados, principalmente na superfície, onde constatou-se o encharcamento do solo nos dias subseqüentes à adubação nitrogenada (Martha Jr., 2003).

Essas perdas por desnitrificação seriam mais expressivas nas doses mais elevadas de $\mathrm{N}$, conforme orienta o trabalho de Veldkamp et al. (1998). A baixa recuperação do ${ }^{15} \mathrm{~N}$-uréia no sistema solo-planta, principalmente nas maiores doses de adubação (i.e. $<35 \%$ do $\mathrm{N}$ aplicado nas adubações maiores que 80 kg/ha de N), dá suporte a essa idéia (Martha Jr., 2003). Esse autor verificou, ainda, que a combinação de elevada umidade do solo, ausência de chuvas durante o primeiro dia depois da adubação e temperatura elevada determinou baixa eficiência agronômica do N-uréia aplicado em pastagem de capimTanzânia.

Em razão do elevado risco de perda do N-uréia aplicado, nessas condições, recomenda-se que estudos futuros considerem as seguintes alternativas para controlar a volatilização de $\mathrm{N}-\mathrm{NH}_{3}$ e, conseqüentemente, aumentar a eficiência de uso do $\mathrm{N}$-fertilizante pelo capim-Tanzânia: 1) o uso de irrigação imediatamente depois da adubação sem, no entanto, favorecer a desnitrificação; 2) o uso de misturas de sais com uréia para determinar se a manipulação da relação N:S do fertilizante, por exemplo, é realmente uma maneira eficaz de controlar as perdas de $\mathrm{N}_{-} \mathrm{NH}_{3}{ }^{-}$em ecossistemas de pastagens tropicais; e 3) o uso de outras fontes de fertilizante nitrogenado menos propensas às perdas de amônia por volatilização, como os sais amoniacais. A utilização de outros fertilizantes nitrogenados, que não a uréia, parece ser, no curto- prazo, a alternativa mais viável tecnicamente (Martha Jr., 1999; Primavesi et al., 2001).

Adicionalmente, tem sido demonstrado que parte do $\mathrm{N}$ volatilizado pode ser absorvido pela cobertura vegetal, o que contribuiria para minimizar as perdas de $\mathrm{N}-\mathrm{NH}_{3}$ do sistema solo-planta. Em estudo recente com capim-Tanzânia, Martha Jr. (2003) observou que 2,5\% (na dose de $120 \mathrm{~kg} /$ ha de $\mathrm{N}$-uréia) a 16,0\% (na dose de $40 \mathrm{~kg} /$ ha de $\mathrm{N}$-uréia) do N volatilizado foi absorvido pelas plantas. Portanto, estudos futuros também deveriam considerar esse aspecto da dinâmica do $\mathrm{N}$ no sistema solo-planta-atmosfera.

\section{Conclusões}

A combinação de elevada umidade do solo, ausência de chuvas durante o primeiro dia depois da adubação e temperatura elevada determinou elevadas perdas de amônia por volatilização, 44\% do $\mathrm{N}$ aplicado na média das adubações com 40, 80 e 120 kg/ha de Nuréia. A volatilização acumulada aumentou com o período depois da adubação, apesar de as taxas de perda de amônia terem sido decrescentes nesse intervalo, sendo constatado maiores valores de volatilização acumulada (kg/ha) nas doses mais elevadas de N-uréia.

\section{Literatura Citada}

BLACK, A.S.; SHERLOCK, R.R.; SMITH, N.P. et al. Effects of form of nitrogen, season, and urea application rate on ammonia volatilisation from pastures. New Zealand Journal of Agricultural Research, v.28, n.4, p.469-474, 1985.

BLACK, A.S.; SHEROLOCK, R.R.; SMITH, N.P. Effect of timing of simulated rainfall on ammonia volatilisation from urea applied to soil of varying moisture content. Journal of Soil Science, v.38, n.4, p.679-688, 1987.

BOUWMEESTER, R.J.B.; VLEK, P.L.G.; STUMPE, J.M. Effect of environmental factors on ammonia volatilization from ureafertilized soils. Soil Science Society of America Journal, v.49, n.2, p.376-381, 1985.

CORSI, M.; MARTHA JR., G.B.; PAGOTTO, D.S. Sistema radicular: dinâmica e resposta a regimes de desfolha. In: SILVA, S.C.; PEDREIRA, C.G.S. (Eds.). A produção animal na visão dos brasileiros - pastagens. Piracicaba: Fundação de Estudos Agrários Luiz de Queiroz, 2001. p.838-852.

CORSI, M.; NUSSIO, L.G. Manejo do capim-elefante: correção e adubação do solo. In: SIMPÓSIO SOBRE O MANEJO DA PASTAGEM, 10., 1992, Piracicaba. Anais...Piracicaba: Fundação de Estudos Agrários Luiz de Queiroz, 1993. p.87-115.

ERNST, J.W.; MASSEY, H.F. The effects of several factors on volatilization of ammonia formed from urea in soil. Soil Science Society of America Proceedings, v.24, n.1, p.87-90, 1960.

GRANLI, T.; BOCKMAN, O.C. Nitrous oxide $\left(\mathrm{N}_{2} \mathrm{O}\right)$ emissions from soils in warm climates. Fertilizer Research, v.42, n.1-3, p.159-163, 1995. 
HARGROVE, W.L. Soil environmental and management factors influencing ammonia volatilization under field conditions. In: BOCK, B.R.; KISSEL, D.E. (Eds.). Ammonia volatilization from urea fertilizers. Muscle Schoals: Tenessee Valley Authority, 1988. p.17-36. (Bulletin, Y-206)

LARA CABEZAS, W.A.R.; TRIVELIN, P.C.O.; BOARETTO, A.E. Efeito do tamanho de grânulos e da relação N/S da uréia aplicada em superfície na volatilização de amônia sob diferentes umidades iniciais do solo. Revista Brasileira de Ciência do Solo, v.16, n.3, p.409-413, 1992.

LARA CABEZAS, W.A.R.; TRIVELIN, P.C.O. Eficiência de um coletor semi-aberto estático na quantificação de $\mathrm{N}-\mathrm{NH}_{3}$ volatilizado da uréia aplicada ao solo. Revista Brasileira de Ciência do Solo, v.14, n.3, p.345-352, 1990.

LARA CABEZAS, W.A.R.; TRIVELIN, P.C.O.; BENDASSOLLI, J.A. et al. Calibration of a semi-open static collector for determination of ammonia volatilization from nitrogen fertilizers. Communications in Soil Science and Plant Analysis, v.30, n.3-4, p.389-406, 1999.

LINN, D.M.; DORAN, J.W. Effect of water-filled pore space on carbon dioxide and nitrous oxide production in tilled and nontilled soils. Soil Science Society of America Journal, v.48, n.6, p.1267-1272, 1984.

MARTHA JR., G.B. Balanço de ${ }^{15} \mathbf{N}$ e perdas de amônia por volatilização em pastagem de capim-elefante. Piracicaba, 1999. 75p. Dissertação (Mestrado) - Escola Superior de Agricultura “Luiz de Queiroz”, Universidade de São Paulo.

MARTHA JR., G.B. Produção de forragem e transformações do nitrogênio do fertilizante em pastagem irrigada de capim-Tanzânia. Piracicaba: Escola Superior de Agricultura “Luiz de Queiroz”, 2003. 149p. Tese (Doutorado) - Escola Superior de Agricultura "Luiz de Queiroz”, 2003.

OLIVEIRA, P.P.A. Manejo da calagem e da fertilização nitrogenada na recuperação de pastagens degradadas de Brachiaria sp. em solos arenosos. Piracicaba: Universidade de São Paulo, 2001. 110p. Tese (Doutorado) - Centro de Energia Nuclear na Agricultura, Universidade de São Paulo, 2001.

PRIMAVESI, O.; CORRÊA, L.A.; PRIMAVESI, A.C. et al. Adubação com uréia em pastagem de Cynodon dactylon cv. Coastcross sob manejo rotacionado: eficiência e perdas. São Carlos: Embrapa Pecuária Sudeste, 2001. 42p. (Circular Técnica, 30)
RAPPAPORT, B.D.; AXLEY, J.H. Potassium chloride for improved urea fertilizer efficiency. Soil Science Society of America Journal, v.48, n.2, p.399-401, 1984.

RODRIGUES, M.B.; KIEHL, J.C. Distribuição e nitrificação da amônia proveniente da uréia aplicada ao solo. Revista Brasileira de Ciência do Solo, v.16, n.3, p.403-408, 1992.

RODRIGUES, M.B.; KIEHL, J.C. Volatilização de amônia após o emprego de uréia em diferentes doses e modos de aplicação. Revista Brasileira de Ciência do Solo, v.10, n.1, p.37-43, 1986.

STATISTICAL ANALYSES SYSTEM - SAS. SAS/STAT user's guide. version 6. 4.ed. Cary: 1989. 943p.

SHARPE, R.R.; HARPER, L.A. Soil, plant and atmospheric conditions as they relate to ammonia volatilization. Fertilizer Research, v.42, n.1-3, p.149-158, 1995.

VELDKAMP, E.; KELLER, M.; NUÑEZ, M. Effects of pasture management on $\mathrm{N}_{2} \mathrm{O}$ and $\mathrm{NO}$ emissions from soils in the humid tropics of Costa Rica. Global Biogeochemical Cycles, v.12, p.71-79, 1998.

VITTI, G.C.; TAVARES JR., J.E.; LUZ, P.H.C. et al. Influência da mistura de sulfato de amônio com uréia sobre a volatilização de nitrogênio amoniacal. Revista Brasileira de Ciência do Solo, v.26, n.3, p.663-671, 2002.

VOLK, G.M. Volatile loss of ammonia following surface application of urea to turf or bare soils. Agronomy Journal, v.51, n.12, p.746-749, 1959.

WATSON, C.J.; STEVENS, R.J.; LAUGHLIN, R.J. et al. Volatilization of ammonia from solid and liquid urea surfaceapplied to perennial ryegrass. Journal of Agricultural Science, v.119, n.2, p.223-226, 1992. 